quelled but merely limited-urged, perhaps, to discovering devices it had not used before. A more general implication of these findings is that the musical element which is functionally strong in a language is the one which intrudes most strongly upon the music associated with it: in our languages the thythmic element, in tone-languages the melodic.

This intimate connexion between speech and music is not to be regarded as supporting the outworn theory, advocated by Herbert Spencer and others, that music originated from speech. It has, however, a bearing on our prevailing notion that music is an 'abstract', self-contained domain. (Communicated by Professor George Herzog, Department of Anthropology, Yale University, U.S.A.)

\title{
A Note on the Abua Language.
}

The Abua language is spoken by about 31,000 people in the district of Ahoada in the Niger Delta. It is one of a number of small languages, investigation into which would be interesting, not so much from a practical point of view, since none of them is likely to be used as a literary medium or to spread in any way, but for the light such investigation might shed on linguistic and cultural relationships. The present writer, while in Nigeria, had the opportunity of noting down certain peculiarities of the sound-system of Abua : a teacher from Ahoada had drawn up an introductory primer of the language and this was used as a basis for the inquiry.

Vowels. A system of nine distinctive vowels was shown in the primer: $i$, $\varepsilon, a, 0, u$ were easy to distinguish, but there were two varieties of 'close' $e$ and of 'close' $o$, which were extremely difficult to analyse. After a considerable number of trials of varying closeness or openness, retracted and advanced tongue-positions, none of which satisfied the informant, it was discovered that the difference lay in the kind of voice used. One type of $e$ and one of $o$ was pronounced with contracted pharynx and another kind of $e$ and of $o$ with open pharynx (and 'breathy' voice). A similar difference was found in two kinds of $\varepsilon$ and $a$, but examples of distinctions in the latter were rare. This type of vowel-distinction has not been found by the present investigator in either Ibo or Ibibio, geographically the nearest important languages. A few examples were subsequently discovered in Kalabari. The vowel-systems of Nuer and Dinka, however, languages of the Eastern Sudan, show a similar characteristic. (See Westermann and Ward, Practical Phonetics for Students of African Languages, pp. 204 and 210, where, in a summary of the sound-system of these languages contributed by Dr. Tucker, a description of such vowels is given.)

Examples:

Abua: $\operatorname{doy}$ (o with open throat), give a parable. $\operatorname{dog}(o$ with contracted throat), be sweet. 
Abua: ena (open throat for both vowels), fish.

Ena (contracted throat for both vowels), stone.

Kalabari: ero (with open throat), mushroom. ero (with contracted throat), small (tones the same).

Consonants. The language makes use of a large number of consonants, including explosive and implosive $b$ and $d$, the labio-velar plosives $k p$ and $g b$, together with the corresponding nasal $g m$ (anmoi, children), a flapped $n$, and retroflex $l$ (as well as the more ordinary $n$ and $l$ ), and the fricatives $f, v, x, \gamma$. The chief peculiarity of the consonant-system, however, as compared with that of Ibo and Ibibio, is the use of fricative consonants finally in a word. This again is a characteristic shared by the Nuer language.

Examples:

esar, sun; erar, three (fricative voiceless $r$ ).

oguux, canoe; odix, rope; kiy, kill.

amupu, lungs; ovav or ovaf, wing.

A number of words were recognizable as being related to either Ibo or one of the Ibibio group: e.g. oyõ, mouth (c.f. Ibo on $\theta$ ); diop (or diof), ten (cf. Efik duop).

A full investigation into the phonetic and grammatical structure of some of the Niger Delta languages would be of great value for the study of comparative linguistics. (Communicated by DR. I. C. WARD, Lecturer in African Linguistics at the London School of Oriental Studies.)

\section{The Racial Situation of Negroes in Cuba.}

The problem of the survival or future development of the Negro race in countries with a white and black population is of growing importance for those parts of Africa where members of the white race increase and thus life becomes an immediate and direct competition between the two races. A new contribution to the study of this problem is made in a book published by the Foreign Policy Association of New York and entitled Problems of the New Cuba. Although not dealing with Africa, it deals with men of African origin, and conditions in Cuba bear a striking resemblance to those in some parts of Africa.

In the first half of the nineteenth century the coloured population of Cuba exceeded the white population in number, while to-day in a total population of four millions only 27 per cent. are coloured. Between the years igr9 and I93 I there was an increase of the total population of 37 per cent., but in the coloured section of only 27 per cent. and in the Spanish of 52 per cent. In recent times there has been a constant influx from Europe. Thus, in I923, I,58I Poles, 1,139 Russians and 2,053 Italians entered the country; there are also 14,000 white Americans, 25,000 Chinese, and Havana has a Jewish 